\title{
Evaluation of Grain Yield Stability Analysis in Bread Wheat (Triticum aestivum L.) Genotypes Using Parametric Method
}

\author{
Gadisa Alemu Wardofa*, Abebe Delesa Ararsa \\ Ethiopian Institute of Agricultural Research, Kulumsa Agricultural Research Center, Asella, Ethiopia
}

Email address:

gadalemu@gmail.com (G. A. Wardofa)

${ }^{*}$ Corresponding author

\section{To cite this article:}

Gadisa Alemu Wardofa, Abebe Delesa Ararsa. Evaluation of Grain Yield Stability Analysis in Bread Wheat (Triticum aestivum L.) Genotypes Using Parametric Method. American Journal of Life Sciences. Vol. 8, No. 6, 2020, pp. 189-195. doi: 10.11648/j.ajls.20200806.12

Received: October 6, 2020; Accepted: October 23, 2020; Published: November 23, 2020

\begin{abstract}
Multi-environment trials have a significant role in selecting the best genotypes to be used at different locations. The study aimed to determine grain yield and stability of 15 bread wheat genotypes in Ethiopia using parametric stability method. Fifteen bread wheat genotypes were evaluated using RCBD with four replications at six locations in Ethiopia in 2017/18 main cropping season. Considering environment, grain yield of environments over genotypes ranged from $2.8 \mathrm{tha}^{-1}$ for Bekoji to $5.15 \mathrm{t} \mathrm{ha}^{-1}$ for Kulumsa. Grain yield of genotypes over environments ranged from $1.53 \mathrm{tha}^{-1}$ to $4.93 \mathrm{tha}^{-1}$. Among the genotypes with above-average mean grain yield $\left(>3.8 \mathrm{t} \mathrm{ha}^{-1}\right)$, ETBW8084 and Hidase were declared stable by all parametric stability parameters except by $\mathrm{S}^{2} \mathrm{i}$ and CV (\%) while ETBW8427 was declared stable by all parametric stability parameters. These three genotypes ranked $6^{\text {th }}, 3^{\text {th }}$ and $4^{\text {rd }}$ by mean grain yield and contributed only $4.5,4.0$ and $4.5 \%$ to SS of GxE interaction, respectively. Hence, they can be recommended for wide adaptation. The genotype ETBW8065 was also among the stable and high yielding genotypes contributing only 6.3\% to GEI. ETBW8078, ETBW8311 and ETBW8459 were low yielding and stable genotypes contributing 1.2, 3.9 and 3.5\% to GEI. ETBW9470, ETBW8070 and ETBW9037 were among the highest yielding genotypes ranking $1^{\text {st }}, 2^{\text {nd }}$ and $5^{\text {th }}$, respectively. However, they were declared unstable by most stability parameters except ETBW8070 which was declared stable by $\mathrm{S}^{2} \mathrm{i}, \mathrm{CV}(\%)$ and Pi stability models. Generally based grain yield ETBW9470 and ETBW8070 genotypes were recommended to crossing block.
\end{abstract}

Keywords: Declared, Environment, GEI and Stable

\section{Introduction}

Wheat (Triticum aestivum L.) is the most widely adapted and cultivated cereal grain in the world. Wheat is a major source of starch and energy, wheat also provides substantial amounts of a number of components which are crucial for health, notably protein, vitamins (notably B vitamins), dietary fiber and phytochemicals [1]. The unique properties of the gluten protein fraction allows the processing of wheat to produce bread, other baked goods, noodles and pasta, and a range of functional ingredients. In Ethiopia, several traditional food items namely 'Dabo'or local bread, 'injera', 'kinche', 'Ambasha', 'kolo'/roasted grain, 'genfo' or porridge, 'shorba' or soup, 'nifro', etc are prepared or produced and consumed. Wheat is well as a strategic, industrial, political and economic crop in Ethiopia. Wheat is the $4^{\text {th }}$ largest (placed after maize, teff and sorghum) cereal crop in terms of areas coverage and production and produced by 5 million small holder farmers on 1.7 million ha of land producing 4.5 million tons annually [2] with average productivity of 2.7 t/ha. In Ethiopia, wheat areas coverage and production have been drastically increased between 2003/04 and 2016/17. However, Ethiopia's wheat production covers only $75 \%$ of its national demand and the remaining $25 \%$ is annually fulfilled through imports [3]. Likewise, the demand is expected to progressively grow due to population growth, urbanization, westernization, increased income and expansion of agroprocessors. On the other hand, wheat productivity is still low (2.7 $\mathrm{t} / \mathrm{ha}$ ) as compared to world average which is $3.1 \mathrm{t} / \mathrm{ha}$ [4] and is constrained by several factors including lack of high yielding, widely adaptable and stable varieties; suboptimal use of good agricultural practices; susceptibility to biotic factors (notably wheat rusts, septoria and weeds); abiotic stresses like drought, heat, frost, acidity, alkalinity, flooding, 
water logging; socio-economic factors namely inappropriate supply and use of inputs like seed, fertilizers, pesticides, mechanization services; inadequate natural resources conservation; etc.

The development of varieties which can be adapted to a wide range of environments is the crucial goal of plant breeders in a crop improvement program [5]. The term stability of genotypes is central to all types of analysis of genotype by environment interactions, especially with reference to plant breeding stability has been described in many different ways over the years and there have also been different concepts of stability [6, 7]. Knowledge of genotypeby-environment interaction presenting valuable information in plant breeding studies can help plant breeders to reduce the cost of extensive genotype evaluation by eliminating unnecessary testing sites [8]. Stability, adaptability and mean yield across all environments are more important than yield for specific environments; hence, cultivars are being selected for a large group of environments [9]. Multi environment yield trial can be analyzed to extract more information on stability, adaptability and yield performance using various statistical methods and software used by different investigators [10-12]. Plant breeders use different methods for analysis of GEI.

There are two major approaches to studying genotype by environment interactions and determining the adaptation of genotypes [13]. Those are parametric analyses, which are based on statistical assumptions about the distribution of genotypic, environmental and GEI effects and nonparametric or analytical clustering, which make no specific modeling assumptions when relating environments and phenotypes relative to biotic and abiotic environmental factors.

Parametric methods for estimating genotype $x$ environment interactions and phenotypic stability are widely used in plant breeding and production. The proper use of these parametric measures requires some statistical assumptions, like showing the normal distribution of errors and interaction effects [10] and may not perform well if these assumptions are violated by factors such as the presence of outliners [14].

Different parametric stability models are available such as the environmental variance $\left(\mathrm{S}^{2} \mathrm{i}\right)$, coefficient of variation $(\mathrm{CV})$, superiority index (Pi), Wricke's ecovalence $\left(\mathrm{W}^{2} \mathrm{i}\right)$, regression and approach (bi), deviation from regression (s2di), Shukla's stability variance, genotypic stability, additive main effect and multiplicative interaction effect (AMMI). AMMI stability value (ASV) is also comparable with the other stability parameters of AMMI model in the study of genotype by environment interaction and yield stability. [7] Recommended that the $S^{2} d i, W^{2} i, \sigma^{2}$ and CV should be used concurrently to estimate phenotypic stability effects. Using parametric stability statistics and their significance tests, assumptions have to be made about distribution and variance homogeneity. To recommend genotypes to the target environment, assessment of stability and using adequate stability measures have paramount importance. Hence, the objective of this study is to determine grain yield and stability of 15 bread wheat genotypes in Ethiopia using parametric stability method.

\section{Materials and Methods}

\subsection{Description of Experimental Site}

The experiment was conducted during 2017/2018 cropping season under conditions at Kulumsa agricultural research center, Asasa, Dhera, Bekoji, Arsi Robe and Holeta agricultural research center.

Table 1. List of test locations and their description.

\begin{tabular}{llllll}
\hline \multirow{2}{*}{ Location } & Geographic position & \multirow{2}{*}{ Altitude } & & \multicolumn{2}{c}{ Temperature ('c) } \\
\cline { 2 - 3 } \cline { 5 - 6 } & Latitude & Longitude & & Min & \multicolumn{2}{c}{ Max } \\
\hline Kulumsa & $08^{\circ} 01^{\prime} 10^{\prime \prime} \mathrm{N}$ & $39^{\circ} 09^{\prime} 11^{\prime \prime} \mathrm{E}$ & 2200 & 10.5 & 22.8 \\
Asasa & $07^{\circ} 07^{\prime} 09^{\prime \prime} \mathrm{N}$ & $39^{\circ} 11^{\prime} 50^{\prime \prime} \mathrm{E}$ & 2340 & 5.8 & 24 \\
Dhera & $08^{\circ} 19^{\prime} 10^{\prime \prime} \mathrm{N}$ & $39^{\circ} 19^{\prime} 13^{\prime \prime} \mathrm{E}$ & 1650 & 14 & 27.8 \\
Bekoji & $07^{\circ} 32^{\prime} 37^{\prime \prime} \mathrm{N}$ & $39^{\circ} 15^{\prime} 21^{\prime \prime} \mathrm{E}$ & 2780 & 7.9 & 18.6 \\
Arsi Robe & $07^{\circ} 53^{\prime} 02^{\prime \prime} \mathrm{N}$ & $39^{\circ} 37^{\prime} 40^{\prime \prime} \mathrm{E}$ & 2420 & 6 & 21.1 \\
Holeta & $09^{\circ} 03^{\prime} 41^{\prime \prime} \mathrm{N}$ & $38^{\circ} 30^{\prime} 44^{\prime \prime} \mathrm{E}$ & 2400 & 6.2 & 22.1 \\
\hline
\end{tabular}

\subsection{Experimental Materials}

Thirteen advanced bread wheat genotypes and two recently released bread wheat varieties were used as treatments for the study.

Table 2. Names and pedigree of the 15 tested genotypes in 2017/18 cropping season.

\begin{tabular}{ll}
\hline Name & Pedigree \\
\hline Lemu & WAXWING*2/HEILO \\
ETBW8070 & Line 1 Singh/ETBW4919 \\
ETBW8078 & Line 1 Singh/(Cham6/WW1402) \\
ETBW8084 & Line 3 Singh/(Cham6/WW1402) \\
ETBW8311 & ND643/2*WBLL1/3/KIRITATI/PRL/2*PASTOR/4/KIRITATI/PBW65/2*SERI. 1B \\
ETBW8065 & Line 1 Singh/ETBW4919 \\
ETBW8427 & SERI. 1B//KAUZ/HEVO/3/AMAD/4/PYN/BAU//MILAN/5/ICARDA-SRRL-1 \\
ETBW8459 & CHIL-1//VEE'S'/SAKER'S' \\
\hline
\end{tabular}




\begin{tabular}{ll}
\hline Name & Pedigree \\
\hline ETBW9037 & SWSR22T. B./2*BLOUK \#1//WBLL1*2/KURUKU \\
ETBW9045 & KINDE/4/CMH75A. 66//H567.71/5*PVN/3/SERI \\
ETBW8075 & Line 1 Singh/(Cham6/WW1402) \\
ETBW9464 & MARCHOUCH*4/SAADA/3/2*FRET2/KUKUNA//FRET2*2/4/TRCH/SRTU//KACHU \\
ETBW9466 & ATTILA/3*BCN//BAV92/3/TILHI/5/BAV92/3/PRL/SARA//TSI/VEE\#5/4/CROC_1/AE. SQUARROSA \\
ETBW9470 & BAVIS//2*OPATA*2/6/HUW234+LR34/PRINIA//UP2338*2/VIVITSI \\
Hidase & YANAC/3/PRL/SARA//TSI/VEE\#5/4/CROC-1/AE. SQUAROSA (224)//OPATTA \\
\hline
\end{tabular}

\subsection{Experimental Design}

The field experiment was laid out in RCBD with four replications per site. The experimental field plot was 6 rows of $2.5 \mathrm{~m}$ long with a $0.2 \mathrm{~m}$ inter-row spacing. Each plot was planted at a seed rate of $150 \mathrm{~kg} \mathrm{ha}^{-1}$. The fertilizer application and other crop management practices were done as per recommendations of each test locations. Weeds grown in the plots were manually removed starting from two weeks after sowing.

\subsection{Data Collection}

Data was collected on the following traits: days to heading, days to maturity, grain filling period, number of grains per spike, number of spikelet per spike, plant height, number of tiller per plant, spike length, biomass yield, harvest index, TKW, HLW and grain yield per plot.

\subsection{Statistical Analysis}

A combined analysis of variance was first undertaken across

Table 3. Mean square of variance combined analysis on yield.

\begin{tabular}{llll}
\hline Source of Variation & D. f & Sum Square & Mean square \\
\hline Genotype & 14 & 206.3 & $14.74^{* * *}$ \\
Rep (Env't) & 18 & 19.03 & 1.05 \\
Environment & 5 & 217.53 & $43.51^{* * *}$ \\
Interactions & 70 & 192.67 & $2.75^{* * *}$ \\
Error & 267 & 98.46 & 0.43 \\
Total & 359 & 733.99 & 35.28 \\
Grand mean=3.77 & C. $\mathrm{V}=16.55$ & & 31.45 \\
\hline
\end{tabular}

Considering environment, grain yield of environments over genotypes ranged from $2.85 \mathrm{tha}^{-1}$ for Bekoji to $5.15 \mathrm{t} /$ ha for Kulumsa. Grain yield of genotypes over environments ranged from $1.53 \mathrm{t} \mathrm{ha}^{-1}$ to $4.93 \mathrm{t} \mathrm{ha}^{-1}$ (Table 4). Considering the grain yield over environments as the first parameter, the following genotypes namely Lemu, ETBW8070, the test environments. Then, parametric stability parameters such as Eberhart and Russel's (1966) the regression coefficient (bi) and deviation from regression $\left(\mathrm{S}^{2} \mathrm{di}\right)$, environmental variance $\left(\mathrm{S}^{2} \mathrm{i}\right)$, Wricks's (1962) ecovalance $\left(\mathrm{W}^{2} \mathrm{i}\right)$, Shukla's (1972) stability variance $\left(\sigma^{2} i\right)$, coefficient of variation $(\mathrm{CV} \%)$ stability parameter and superiority index $(\mathrm{Pi})$ were analyzed by using R-software [15].

\section{Results and Discussion}

A combined analysis of variance for grain yield of the 15 bread wheat genotypes tested across 6 environments is presented in Table 3. Results revealed significant difference $(\mathrm{P} \leq 0.001)$ for environment, genotypes and GEI. The effects of environment, genotypes and GEI accounted for $35.28 \%$, $33.46 \%$ and $31.45 \%$ of total sum of squares, respectively (Table 3). A large sum of squares evaluation for environment indicated that environments were diverse and this caused the most variation in grain yield.
ETBW8084, ETBW8065, ETBE8427, ETBW9037, ETBW9045, ETBW9466, ETBW9470 and Hidase produced higher grain yield than grand mean grain yields $\left(3.77 \mathrm{t} \mathrm{ha}^{-1}\right)$. On the other hand, genotypes ETBW8078, ETBW8311, ETBW8459 and ETBW8075 had lower values than mean grain yield (Table 4).

Table 4. Mean yield of fifteen bread wheat genotypes tested across six environments $\left(t h a^{-1}\right)$.

\begin{tabular}{|c|c|c|c|c|c|c|c|}
\hline Genotype & Bekoji & Dhera & A. Robe & Holeta & Asasa & Kulumsa & Mean \\
\hline Lemu & 3.25 & 3.00 & 3.65 & 5.34 & 3.76 & 4.57 & 3.93 \\
\hline ETBW8070 & 4.81 & 3.44 & 3.86 & 5.86 & 5.10 & 4.55 & 4.60 \\
\hline ETBW8078 & 2.04 & 3.15 & 3.27 & 3.31 & 3.61 & 4.95 & 3.39 \\
\hline ETBW8084 & 2.66 & 2.90 & 4.08 & 3.43 & 4.89 & 6.36 & 4.05 \\
\hline ETBW8311 & 1.25 & 3.05 & 3.31 & 2.69 & 3.88 & 4.50 & 3.11 \\
\hline ETBW8065 & 3.25 & 3.49 & 2.35 & 4.96 & 4.87 & 4.56 & 3.91 \\
\hline ETBW8427 & 4.07 & 2.76 & 3.30 & 4.84 & 4.70 & 5.30 & 4.16 \\
\hline ETBW9037 & 3.82 & 1.95 & 2.97 & 4.85 & 5.07 & 5.99 & 4.11 \\
\hline ETBW9045 & 4.50 & 2.44 & 3.18 & 3.39 & 4.85 & 5.04 & 3.90 \\
\hline ETBW8075 & 0.38 & 3.21 & 0.91 & 1.23 & 1.24 & 2.23 & 1.53 \\
\hline ETBW9464 & 0.84 & 3.45 & 3.01 & 3.28 & 3.80 & 5.72 & 3.35 \\
\hline
\end{tabular}




\begin{tabular}{|c|c|c|c|c|c|c|c|}
\hline Genotype & Bekoji & Dhera & A. Robe & Holeta & Asasa & Kulumsa & Mean \\
\hline ETBW9466 & 2.74 & 3.87 & 3.49 & 2.86 & 4.08 & 6.43 & 3.91 \\
\hline ETBW9470 & 4.01 & 3.66 & 5.69 & 3.41 & 6.25 & 6.56 & 4.93 \\
\hline Hidase & 2.62 & 3.79 & 3.56 & 5.45 & 4.37 & 5.94 & 4.29 \\
\hline Mean & 2.85 & 3.17 & 3.32 & 3.82 & 4.33 & 5.15 & 3.77 \\
\hline
\end{tabular}

\subsection{Environmental Variance}

The environmental variance $\left(\mathrm{S}_{\mathrm{i}}^{2}\right)$ is one of the major stability measures for the static stability concept, i.e., the variance of genotype yields recorded across test environments. The smaller the environmental variance, the more stable is the genotype and where the environmental variance is larger the more unstable the genotype performance across testing environments is. According to the environmental variance ETBW8070, Lemu, ETBW8459, ETBW8078, and ETBW8427 were the most stable genotypes with mean yields of $4.6 \mathrm{t} / \mathrm{ha}, 3.93 \mathrm{t} / \mathrm{ha}$ and $3.45 \mathrm{t} / \mathrm{ha}, 3.39 \mathrm{t} / \mathrm{ha}$ and $4.16 \mathrm{t} / \mathrm{ha}$, respectively. Thus, ETBW8070 and ETBW8427 can be recommended for wider adaptation since they had above average mean yield and ranked $2^{\text {nd }}$ and $4^{\text {th }}$ by mean grain yield. They possessed static stability. Out of the tested genotypes, the highest four yielding genotypes namely ETBW8084, ETBW9470, Hidase and ETBW9037 ranked $12^{\text {th }}, 13^{\text {th }}, 10^{\text {th }}$ and $14^{\text {th }}$ by stability as measured by $\mathrm{S}^{2} \mathrm{i}$. Thus, they were unstable and adapted to only few environments (Table 5).

\subsection{Stability Analysis According to Eberhart and Russell (1966)}

The measures of adaptability and stability are important for its suggestion to target environments for selecting genotypes. According to [16] regression coefficients (bi) approximating 1.0 coupled with deviation from regression (S2di) of zero indicate average stability. Genotypes have general adaptability when associated with high mean yield while genotypes are poorly adapted to environments when associated with low mean yield. Regression coefficient (bi) values above 1.0 define genotypes with higher sensitivity to environmental fluctuations. Genotype with bi value less than 1.0 has above average stability and is specifically adaptable to low-yielding environments. A genotype with bi value greater than 1.0 has below average stability and specifically adaptable to high yielding environments and a genotype with bi value equal to 1.0 has average stability and is poorly adaptable to all environments if it gives low yield, but well adapted to all environments if it gives high yield [17].

Regression coefficient (bi) values above 1.0 define genotypes with higher sensitivity to environmental alteration. Regression coefficients (bi) decreasing below 1.0 ensure a measure of greater resistance to environmental variation, and hence, increasing specificity of adaptability to low yielding environments. Genotypes, ETBW8084, ETBW9470 and ETBW9045 had higher grain yields and a coefficient values greater than 1.0. These genotypes are sensitive to environmental fluctuations and would be recommended for cultivation in high yielding environments and suitable for favorable growing conditions with appropriate agronomic practices. Similarly, [18, 19] those reported those bread wheat genotypes that had higher grain yields and a coefficient values greater than 1.0 are sensitive to environmental variations and would be suggested for cultivation under favorable conditions.

The genotypes ETBW8075 (bi=0.31) had a regression coefficient less than one $(\mathrm{bi}<1.0)$, therefore these genotypes is poorly adaptable to all environments and recommended for low-yielding environments that require good agronomic practices. [18 and 19] those reported that spring bread wheat genotype with $b i<1$ and lowest average yields were poorly adapted across environments and might have specific adaptation to harsh conditions. Genotype ETBW8070 (bi=0.31) had low bi values and highest average yields. ETBW8070 ranked $2^{\text {nd }}$ by mean grain yield but had below average responsiveness to improved environments. It was in the top $1 / 3^{\text {rd }}$ at Asasa, Bekoji, Arsi Robe and Holeta, $6^{\text {th }}$ at Kulumsa and $13^{\text {th }}$ at Dhera. Such genotypes are rare; usually high yielding genotypes have bi values greater than 1.0. The genotypes ETBW8427 was determined as the best genotypes for wide scale release (broad adaptability) since they had higher grain yield above average yield, regression coefficient values (bi) near to one and low deviation from the regression S2di (i.e. regression coefficient not significantly different from 1.0.)

\subsection{Wricke's Eco-valence Analysis $\left(W^{2} i\right)$}

The lower the values of W2i have the smaller fluctuations from the predictable response in different environments so that the genotype with the least eco-valence is considered to be ideal from the point of view of yield stability. Stability analysis in the performance of genotypes across environments using Wricke'secovalence (Wi) showed that ETBW8078 and ETBW8459 was more stable in grain yield as its contributions to the GXE interaction sum of squares was the least (Table 4). This result suggests that selection for genotypic performance stability based on $\mathrm{W}^{2} \mathrm{i}$ parameters favors' below-average-yielding over high yielding bread wheat genotypes. Similarly, Schoeman (2003) reported that genotypes with the lowest ecovalence contribute less to GEI but have lower yield and are sensitive to environment interactions whereas genotypes with both good stability and yield show good adaptability to their test environments. [20] also reported that low-yielding lentil genotypes were the most stable compared to high-yielding ones, using the same parameters. The most interactive and unstable genotypes based on the eco-valence method were ETBW8075, ETBW8070, ETBW9470, ETBW9037 and ETBW9464. These genotypes had high Wi ecovalance contribute largely to the GEI. Similarly, [21] also indicated that genotypes with 
high Wi ecovalance contribute largely to the GEI and are unstable in malt barley. [22] on bean genotypes, [23] on wheat genotypes, [24] on wheat genotypes, and [25] on coffee genotypes used this stability parameter for evaluation of their respective genotypes stability performance. [24] identified the most stable and high yielding durum wheat genotypes by using different stability measures.

\subsection{Shukla's Stability Variance $\left(\delta^{2}\right)$}

Shukla's (1972) stability variance values and the stability ranking as well as the mean yield with its ranking are given in Table 4. According to this stability parameter the most stable genotypes were ETBW8078, ETBW8459, ETBW8311, ETBW8427 and ETBW8084 while, the most unstable genotypes were ETBW8075, ETBW8070, ETBW9470, ETBW9037 and ETBW9464 (Table 5). Several studies have been undertaken in order to evaluate wheat genotypes stability across different agro ecological environments using Shukla's stability variance $[23,24,26$, 27].

\subsection{Coefficient of Variation Stability Parameter}

The genotypes with low variability across the locations are normally considered as stable/widely adapted genotypes, while high $\mathrm{CV}$ indicated narrowly adapted genotype/unstable. Hence according to this stability parameter the following genotypes fall into the high yield and low variation group and can be considered the most stable ETBW8070, ETBW8427, Lemu, ETBW9065, ETBW9045, ETBW9470 and Hidase. However, the genotype ETBW8075 was the most interactive genotype with higher coefficient variability (Figure 1 and Table 5).

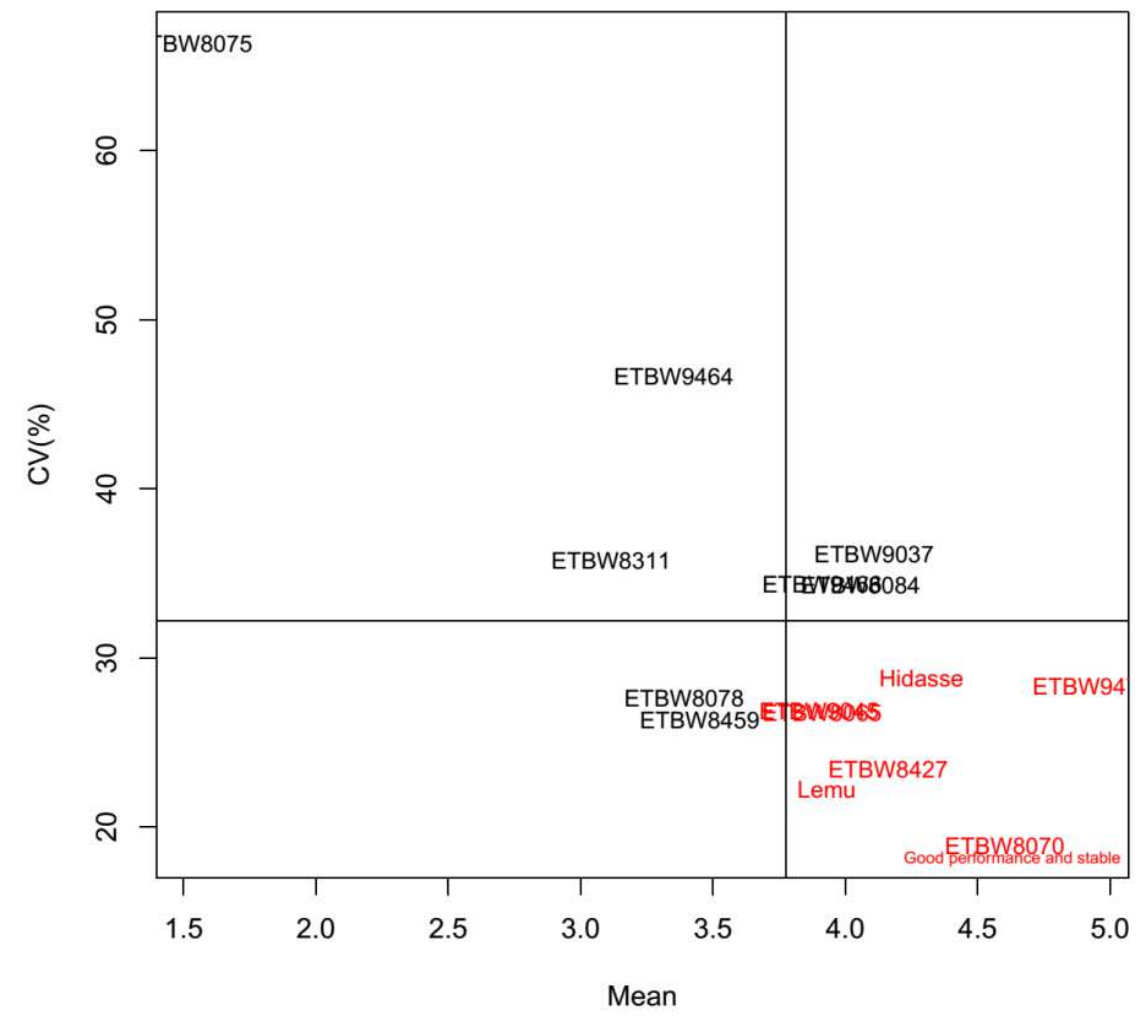

Figure 1. Coefficient of variation stability parameter.

\subsection{Lin and Binns Superiority Measure}

Genotype with the lowest (Pi) value is considered as stable. The genotypes ETBW9470, ETBW8070, ETBW8427, Hidase and Lemu were with lower Lin and Binns's genotype performance measure and as a result they were stable genotypes. ETBW8075 was with higher Lin and Binns's cultivar performance measure and was the most unstable genotype coupled with the lowest grain yield (Table 5).

Table 5. Mean grain yield, univariate stability analysis of 15 bread wheat genotypes across different environments.

\begin{tabular}{|c|c|c|c|c|c|c|c|c|c|c|c|}
\hline SN & Genotype & Yield & $\mathbf{R}$ & $\mathbf{S}_{i}^{2}$ & $b i$ & $S_{d i}^{2}$ & $W_{i}$ & $\delta^{2}$ & CV (\%) & $\mathbf{R}^{2}$ & $\mathbf{P i}$ \\
\hline 1 & Lemu & 3.93 & 7 & 0.76 & 0.60 & $0.53^{* * *}$ & $12.45^{* * *}$ & 2.66 & 22.24 & 0.34 & 1.48 \\
\hline 2 & ETBW8070 & 4.60 & 2 & 0.75 & 0.31 & $0.76^{* * *}$ & $20.68^{* * *}$ & 4.55 & 18.88 & 0.09 & 0.74 \\
\hline 3 & ETBW8078 & 3.39 & 12 & 0.88 & 1.02 & 0.05 & 2.38 & 0.33 & 27.61 & 0.86 & 2.51 \\
\hline 4 & ETBW8084 & 4.06 & 6 & 1.94 & 1.54 & $0.17^{*}$ & $8.58^{*}$ & 1.77 & 34.31 & 0.89 & 1.32 \\
\hline 5 & ETBW8311 & 3.12 & 14 & 1.24 & 1.10 & $0.36^{* *}$ & $7.48^{* *}$ & 1.51 & 35.76 & 0.70 & 3.24 \\
\hline 6 & ETBW8065 & 3.91 & 9 & 1.09 & 0.84 & $0.63^{* * *}$ & $12.08^{* * *}$ & 2.57 & 26.74 & 0.47 & 1.71 \\
\hline 7 & ETBW8427 & 4.16 & 4 & 0.95 & 0.89 & $0.37^{* * *}$ & $7.73^{* * *}$ & 1.57 & 23.42 & 0.60 & 1.04 \\
\hline
\end{tabular}




\begin{tabular}{|c|c|c|c|c|c|c|c|c|c|c|c|}
\hline SN & Genotype & Yield & $\mathbf{R}$ & $\mathbf{S}_{\mathrm{i}}^{2}$ & $\overline{b i}$ & $S_{d i}^{2}$ & $W_{i}$ & $\delta^{2}$ & CV (\%) & $\mathbf{R}^{2}$ & $\mathbf{P i}$ \\
\hline 9 & ETBW9037 & 4.11 & 5 & 2.21 & 1.45 & $0.77^{* * *}$ & $16.66^{* * *}$ & 3.63 & 36.15 & 0.69 & 1.23 \\
\hline 10 & ETBW9045 & 3.90 & 10 & 1.10 & 0.76 & $0.76^{* * *}$ & $14.54^{* * *}$ & 3.14 & 26.86 & 0.38 & 1.57 \\
\hline 11 & ETBW8075 & 1.53 & 15 & 1.04 & 0.31 & $1.11^{* * *}$ & $26.32^{* * *}$ & 5.86 & 66.32 & 0.07 & 9.01 \\
\hline 12 & ETBW9464 & 3.35 & 13 & 2.45 & 1.63 & $0.55^{* * *}$ & $16.18^{* * *}$ & 3.53 & 46.67 & 0.79 & 3.04 \\
\hline 13 & ETBW9466 & 3.91 & 8 & 1.81 & 1.33 & $0.56^{* * *}$ & $12.14^{* * *}$ & 2.59 & 34.35 & 0.71 & 1.90 \\
\hline 14 & ETBW9470 & 4.93 & 1 & 1.95 & 1.15 & $1.14^{* * *}$ & $20.09^{* * *}$ & 4.43 & 28.30 & 0.49 & 0.56 \\
\hline 15 & Hidase & 4.29 & 3 & 1.53 & 1.25 & $0.39^{* * *}$ & $8.74^{* * *}$ & 1.81 & 28.81 & 0.74 & 1.12 \\
\hline
\end{tabular}

Where; Yield $=$ mean grain yield, $\mathrm{R}=$ rank, $\mathrm{S}^{2} \mathrm{i}=$ environmental variance, $\mathrm{bi}=$ regression coefficient, $\mathrm{S}^{2} \mathrm{di}=$ deviation from regression, $\mathrm{WI}=\mathrm{Wricke}$ 's ecovalence analysis, $\sigma^{2}=$ Shukla's Stability Variance, $\mathrm{CV}=$ coefficient of variation, $\mathrm{Pi}=$ superiority index, $\mathrm{R}^{2}=$ coefficient of determination.

\section{Conclusion}

Bread wheat genotypes showed differences in stability and performance across environment and the importance of genotype by environment interactions were observed. Among the genotypes with above-average mean grain yield $(>3.8 \mathrm{t}$ $\left.\mathrm{ha}^{-1}\right)$, ETBW8084 and Hidase were declared stable by all stability parameters except by $\mathrm{S}^{2} \mathrm{i}$ while ETBW8427 was declared stable by all stability parameters. These three genotypes ranked $6^{\text {th }}, 3^{\text {rd }}$ and $4^{\text {th }}$ by mean grain yield and contributed only $4.5,4.0$ and $4.5 \%$ to SS of GxE interaction, respectively. Thus, they can be recommended for wide adaptation. Likewise, ETBW8065 was among the stable and high yielding genotypes contributing only $6.3 \%$ to GEI. The genotypes ETBW8078, ETBW8311 and ETBW8459 were low yielding and stable genotypes contributing 1.2, 3.9 and $3.5 \%$ to GEI, respectively. The genotypes ETBW9470, ETBW8070 and ETBW9037 were among the highest yielding genotypes ranking $1^{\text {st }}, 2^{\text {nd }}$ and $5^{\text {th }}$, respectively. However, they were declared unstable by most stability parameters except ETBW8070 which was declared stable by $\mathrm{S}^{2} \mathrm{i}, \mathrm{CV}(\%)$ and Pi. Generally based grain yield ETBW9470 and ETBW8070 genotypes were recommended to crossing block.

\section{Acknowledgements}

Authors are grateful to Ethiopian Institute of Agricultural Research for financial support and Kulumsa Agricultural Research Center for provision of facilities and implementation of the experiment.

\section{References}

[1] Shewry, P. R. and S. J. Hey. 2015. The contribution of wheat to human diet and health. Food Energy Security, 4 (3): 178202.

[2] Eyob Bezabeh, Tesfaye Haregewoin, Dejene Hailegiorgis, Fitsum Daniel and Baye Belay. 2014. Change and growth rate analysis in area, yield and production of wheat in Ethiopia. International Journal of Development Research, 4 (10): 1994-1995.

[3] Solomon, T., Y. Shewaye, H. Zegeye, D. Asnake, Z. Tadesse and B. Girma. 2018. Performance Evaluation of Advanced Bread Wheat Genotypes for Yield Stability Using the AMMI Stability Model. J Agri Res 2018, 3 (4): 000168.
[4] Mohebodini, M., H. Dehghani and S. H. Sabaghpour (2006). Stability of performance in lentil (Lens culinarisMedik) genotypes in Iran. Euphytica, 149: 343-352.

[5] Lin, C. S. and M. R. Binns. 1988. A superiority measure of cultivar performance for cultivar $\mathrm{x}$ location data. Can. J. Plant Sci., 68: 193-198.

[6] Fasahat P, Rajabi A, Mahmoudi SB, Noghabi MA, Rad JM. 2015. An Overview on the Use of Stability Parameters in Plant Breeding. Biom Biostat Int J 2 (5): 00043.

[7] Letta, T. (2009). Genotype environment interactions and correlation among stability parameters yield in durum wheat (Triticum durum Desf) genotypes grown in south east Ethiopia. African Crop Science Proceedings. 8: 693-698.

[8] Piepho, H. P. (1996). Analysis of Genotype-by environment and Phenotypic Stability. In: Kang M. S and Zobel Jr H. G (Eds). Genotype by Environment. CRC Press. Boca Raton, pp: 151-174.

[9] Hussein, M. A., B. Asmund and A. H. Aastveit. 2000. SASG $X$ ESTAB: A SAS Program for computing genotype $X$ environment stability statistics. Agron. J., 92: 454-459.

[10] Gauch, H. G. 2006. Statistical analysis of yield trials by AMMI and GGE. Crop Sci., 46: 1488-1500.

[11] Huehn M. 1990. Nonparametric measures of phenotypic stability: I. Theory. Euphytica 47: 189-194.

[12] Yan, W., M. S. Kang, B. Ma, S. Woods and P. L. Cornelius (2007). GGE- biplot vs. AMMI analysis of genotype-byenvironment data. Crop Sci., 47: 643-655.

[13] Huehn M. 1996. Non-parametric analysis of genotype $x$ environment interactions by ranks. In: Kang MS and Gauch HG (eds) Genotype by Environment Interaction. CRC Press, Boca Raton, pp 213-228.

[14] Mangiafico, S. S. 2015. An R Companion for the Handbook of Biological Statistics, version 1.3.2.

[15] Eberhart, S. A. and Russell, W. A., 1966. Stability parameters for comparing varieties. Crop science 6: 36-40.

[16] Finlay, K. W. and Wilkinson, G. N., 1963. The analysis of adaptation in a plants breeding programme. Australian Journal of Agricultural Research 14: 742-754.

[17] Kilic, H. (2012). Assessment of parametric and nonparametric methods for selecting stable and adapted spring bread wheat genotypes in multienvironments. The J. Anim. Plant Sci. 22 (2): 2012, Page: 390-398.

[18] Yaghotipoor. A, E. Farshadfar and M. Saeidi. 2017. Evaluation of phenotypic stability in bread wheat accessions using parametric and non-parametric methods. The J. Anim. Plant Sci. 27 (3): 1269-1275. 
[19] CSA (Central Statistical Agency of Ethiopia). 2017. Agricultural sample survey report on area and production of crops. Stat. Bul. Vol. 1. No. 584.

[20] Karimizadeh, R, M. Mohammadi, N. Sabaghnia, M,. K. Shefazadeh \& J. Pouralhossini. 2012. Univariate stability analysis methods for determining genotype $\times$ environment interaction of durum wheat grain yield. African J. Biot. 11: 2563-2573.

[21] Bantayehu, M. (2009): Analysis and correlation of stability parameters in malting barley. African Crop Science Journal 17 (3): 145-153.

[22] Asfaw, A., Blair, M. W. and Almekinders, C. 2009. Genetic diversity and population structure of common bean (Phaseolus vulgaris L.) landraces from the East African highlands. Th. App. Geneti. 120 (1), pp. 1-12.

[23] Debelo D., Gelalcha S., Yaie B., Girma B., Mamo B. \&Masresha, D. 2004, November. Grain Yield Stability of Bread Wheat Genotypes in Favorable and Stressed Environments. In Proceedings of the 12th Regional Wheat Workshop for Eastern, Central and Southern Africa. 76p.
[24] Fentaw Abate. 2011. Genotype x environment interaction and stability analysis for yield of durum wheat (Triticum turgidumdesf.) varieties in north western Ethiopia. An MSc Thesis Presented to the School of Graduate Studies of Haramaya University. 85p.

[25] Lemi Beksisa. 2016. Genotype by environment interaction and stability analysis of Arabica genotypes advanced limu coffee genotypes in South western Ethiopia. Unpublished Msc. Thesis Jimma University, Ethiopia.

[26] Purchase, J. L., Hesta Hatting and C. S. van Deventer. 2000. Genotype $\times$ environment interaction of winter wheat (Triticum aestivum L.) in South Africa: II. Stability analysis of yield performance, South African Journal of Plant and Soil, 17: 3, 101-107.

[27] Akcura, M., Y. Kaya, S. Taner and R. Ayranci. 2006. Parametric stability analyses for grain yield of durum wheat. PLANT SOIL ENVIRON, 52 (6): 254-261. 